INTERNATIONAL JOURNAL OF RESEARCHES IN BIOSCIENCES, AGRICULTURE AND TECHNOLOGY (C) VISHWASHANTI MULTIPURPOSE SOCIETY (Global Peace Multipurpose Society) R. No. MH-659/13(N) www.vmsindia.org

\title{
COMPOSITION, PHASE ANALYSIS, MICROSTRUCTURE AND MAGNETIC PROPERTIES OF ULTRAFINE AL-SUBSTITUTED SR-HEXAFERRITE NANO POWDERS PREPARED BY SOL-GEL AUTO COMBUSTION METHOD
}

\author{
S. A. Pawade ${ }^{1}$, P. Moharkar ${ }^{2}$, S. Gawali ${ }^{3}$, \\ V. M. Nanoti 4 and K. G. Rewatkar 5 \\ 1Department of Applied Physics, Rajiv Gandhi College of Engineering, Chandrapur \\ ${ }^{2}$ Department of Physics Arts,commerce, science College Chandrapur \\ ${ }^{3}$ Dept of Physics, Dr, Ambedkar College, Chandrapur \\ ${ }^{4}$ Department of Applied Physics, Priyadarshini College of Engineering, Nagpur \\ ${ }^{5}$ Department of Physics, Dr. Ambedkar College, Nagpur
}

\begin{abstract}
:
Al-substituted M-type hexaferrite is a highly anisotropic ferromagnetic material. In the present study, Microwave solgelauto combustion method for synthesis of $\mathrm{SrLa}_{y} \mathrm{Fe}_{12-\mathrm{x}-\mathrm{y}} \mathrm{Al}_{\mathrm{x}} \mathrm{O}_{19}$ powders were explored . It was attempted to prepare aluminum-substituted strontium hexaferrites with compositions $\mathrm{Sr} \mathrm{La}_{\mathrm{y}} \mathrm{Al}_{\mathrm{x}} \mathrm{Fe}_{12-\mathrm{x}-\mathrm{y}} \mathrm{O}_{19}$ having $\mathrm{x}=0,2,4,6$, and 8 . The precursors were prepared by using stoichiometric amounts of $\mathrm{Sr}, \mathrm{Al}$ and $\mathrm{Fe}^{3+}$ nitrate solutions with urea as the precipitating agent. The hydrothermally prepared precursors were calcined at temperatures in the range of $800-1200{ }^{\circ} \mathrm{C}$.It shows hexagonal magnetoplumbite (M) structure having unit cell dimensions ' $a$ ' and ' $\mathrm{c}$ ' varies between 5-6 $\AA$ and $21-23 \AA$ with same space group P63/mmc (No. 194). The temperature dependent electrical conductivity measurements were carried out at 300-650 K. The compounds are ferromagnetic nature upto Curie temperature and above this show paramagnetic nature. The activation energy has been observed more in paramagnetic region than ferromagnetic region. The temperature dependent magnetic susceptibility measurement has been carried out and from this Curie molar constant has been found to decrease with the increase in Al concentration with respect to Curie temperature. There is no significant variation in lattice parameter with $\mathrm{Al}$ concentration. The experimental results have shown that $\mathrm{Al}^{3+}$ ions substitute $\mathrm{Fe}^{3+}$ ions in the sublattice, and the samples remain in the hexagonal magneto plumbite phase. The saturation magnetization $\mathrm{M}_{\mathrm{s}}$ and remanence $\mathrm{M}_{\mathrm{r}}$ of $\mathrm{M}$-type $\mathrm{Sr} \mathrm{La} \mathrm{Al}_{\mathrm{x}} \mathrm{Fe}_{12-\mathrm{x}-\mathrm{y}} \mathrm{O}_{19}$ nano particles linearly decrease when $\mathrm{x}$ increases.

Keywords : XRD; hexagonal ferrite; porosity; magnetic susceptibility etc.
\end{abstract}

\section{Introduction :}

$M$-type hexaferrites possess excellent magnetic properties, a relatively high magnetocrystalline anisotropic field, and platelike morphology. This makes this type of ferrite very suitable for microwave devices, computer memory chip, perpendicular magnetic recording, radio frequency coil, transformer coils and antennas etc Certain cation substitutions have been shown to further change the anisotropy such as the $\mathrm{Al}$ substituted Ba-hexaferrite powder and Sr-hexaferrite film[1,2].Many process routes have been devised for the preparation of hexaferrite powders with refined particle size, narrow particle-size distribution, minimal particle agglomeration, and high crystallinity In recent years, the sol-gel combustion process has been widely studied for the synthesis of this type of ferrite powders $[3,4,5,6]$. Various chelating agents have been explored for the formation of homogenous, stable, and transparent sol solutions, and likewise, various reducing agents such ascitric acid [5,6], stearic acid[3](Wang et al 1996) glycine, and urea[4] have been studied to find out the one that supplies the requisite energy to initiate the exothermic reaction amongst oxidants. These studies are important since the synthesis route can affect the characteristics of the synthesized powders. microwave devices, computer memory chip, perpendicular magnetic recording, radio frequency coil, transformer coils and antennas etc. In the present communication, we report the results concerned with the influence of $\mathrm{Al}$ substitution on structural, magnetic and electrical properties of Sr-la ferrite system. The lattice behavior of the $M$ ferrite are also studied

Experimental Details : In this investigation the different compositions of alloying metals (Al) in Sr La ${ }_{y} \mathrm{Al}_{x} \mathrm{Fe}_{12-x}-y \mathrm{O}_{19}$, where (0 $\left.\leq \mathbf{x} \leq \mathbf{8}\right)$ were synthesized by solgelauto combustion method. The pellets of $15 \mathrm{~mm}$ diameter were prepared and sintered $1040^{\circ} \mathrm{C}$ in air atmosphere for about $24 \mathrm{~h}$ using a microprocessor-controlled furnace. The lattice constants of the powders were calculated using the $d, h, k$, and $l$ values of the strong (110), (008), (107),(114), (203), (2011), and (220) peaks in the XRD patterns according to the equation

$\mathrm{d}^{2}(\mathrm{hkl})=\frac{3 a 2}{4(h 2+h k+k 2)}$

The unit cell volume (Vcell) of the hexagonal system was calculated as follows

Vcell $=0.866 a^{2} c$,

where the numeric factor is constant for the hexagonal system. The XRD patterns have been taken to identify the phases formed and to confirm the chemical reaction by using Phillips $\mathrm{X}$-ray diffractometer using CuKa-radiationX-ray 
diffraction pattern showed a single crystalline phase without traces of impurities. The patterns have been indexed to hexagonal magnetoplumbite structure pertaining to the space group P63/mmc (No. 194).

The lattice parameters and x-ray densities of the samples have been calculated from Xray diffraction pattern. The sintered density has been determined by mass and bulk volume of samples from which the porosity for each samples found out. Electrical conductivity measurements have been carried out by two probe method from room temperature to $650 \mathrm{~K}$ using a LCR-Q meter-sortor (Aplab-4912). Electrical resistivity has been measured by the methods and equipment used as described elsewhere[7, 8]. The conductivity was measured at various temperatures from 300-650 K.

\section{Results and Discussion :}

The typical X-ray diffraction pattern of $\mathrm{SrLa}_{y} \mathrm{Fe}_{12-\mathrm{x}-\mathrm{y}} \mathrm{O}_{19}(0 \leq \mathrm{x} \leq 8)$ ofall samples have been shown in Fig. 1. The narrowing of the area of peak is attributed to the enhancement in crystalline size and the high intensities result from decreasing degree of disorder in the $g$ The grinding process for $15 \mathrm{hr}$ leads to powders with a fine grain microstructure and average grain size is reduced to about calculated from Scherrer formula. The intensities of diffraction peaks of the compounds are 10-47Aohigher, which is probably due to the relaxation of internal strain forming during the milling process. The pattern for the samples annealed at temperature $1040^{\circ} \mathrm{C}$ indexes well on the hexagonal magneto plumbite (M-type) structure of space group $\mathrm{P} 63 / \mathrm{mmc}$. The crystallographic analysis of the studied samples shows single phase with magnetoplumbite structure. It has been observed that the XRD pattern for all the five samples contain common planes viz. (0 0 6), $\left(\begin{array}{lll}1 & 0 & 6\end{array}\right),\left(\begin{array}{lll}1 & 1 & 3\end{array}\right),\left(\begin{array}{lll}2 & 0 & 0\end{array}\right)\left(\begin{array}{ll}107\end{array}\right)$ etc. individually with almost same intensity, this shows the resemblance in crystal structure. The volume and density of crystal structure indicates the doping concentration in various sites is proportional to the replaced ions.

Transmission electron microscope showed that all the ferrite samples have crack free and well packed continuous grain structure with continuous grain boundaries Fig. 2The hexaferrite powder consists of hexagonal crystals with average grain size is found to be $43.78 \mathrm{~nm}$ for $\mathrm{SrLaAl}_{4} \mathrm{Fe}_{7} \mathrm{O}_{19}$. which increases with increasing Al content. The electron diffraction shows ring pattern superimposed with spots, revealing the poly-crystallinity of individual crystallites.

Log ovs inverse temperature plot has been found to be linear with a kink to the Curie temperature as shown in Fig. 4

The percentage porosity (p) of the samples has been calculated as depicted in Table- 1 and is plotted againstAl ${ }^{+3}$ concentration Fig. 3. It shows decline trend with increase in dopant concentration. This is due to the fact that the values of lattice parameter decrease with increasing $\mathrm{Al}^{+3}$ concentration, which leads to decrease in porosity. In this context another reason might be the difference in melting points of the reacting oxides used. The number of pores gets reduced at higher temperature as a result of which the individual grains come closer to each other and effective cross-sectional area of grain-to-grain contact increases. This in turn results in greater densification and less porosity as reported [9].lattice constant 'a' undergoes slow variation with substitution $\mathrm{x}$. Lattice constant ' $c$ ' rapidly decreases linearly at lower substitution and slows down at a higher substitution which shows that ' $c$ ' is more susceptible to stoichiometric changes than 'a' It follows the fact that all hexagonal ferrites exhibit constant lattice parameter 'a' and variable parameter ' $c$ ' [10]. There is a decrease in the values of ' $c$ ' with dopant concentration ' $x$ ' pertaining to the fact the ionic radii of doping ions $\mathrm{Al}^{3+}(0 \cdot 50 \AA)$ compared with $\mathrm{Fe}^{3+}(0 \cdot 64 \AA)$. As the doping concentration increases other intermediate phases like hematite, magnetite lowered down in the intensities. The small particle size of precursor powder increases the diffusion area of the particles thus enhancing the volume diffusion The $\mathrm{Fe}+3$ ions accommodate in five different sites i.e. $2 \mathrm{a}, 2 \mathrm{~b}, 95$ $4 \mathrm{f} 1,4 \mathrm{f} 2$ and $12 \mathrm{~K}$ with different concentration. When it is being replaced by doping, it may perturb the crystal lattice. Similar results have been observed in $\mathrm{Ba} / \mathrm{Ca}$ ferrite systems [11].The variation in the lattice parameter results in the variation of cell volume and x-raydensity which in turn influence the porosity of the compounds. The mean crystalline size of the sample calcinated at $1040^{\circ} \mathrm{C}$ has been estimated from the XRD line width of the $\left(\begin{array}{lll}1 & 1 & 3\end{array}\right)$ peak using the Scherrer equation, $\mathrm{d}=0.9 \lambda / \mathrm{b} \cos \theta$

The activation energy have been found to be in the range of 0.24 to $1.1 \mathrm{eVin}$ the paramagnetic region and about 0.40 to $0.52 \mathrm{eV}$ in ferrimagnetic region. as depicted in Table 2. In the paramagnetic region, the activation energy increases dueto valence exchange mechanis $\mathrm{m}$ between $\mathrm{Fe}^{+3}$ and $\mathrm{Fe}^{+2}[12,13]$. 
The plot of inverse magnetic susceptibility vs temperature is linear above Curie temperature, which resembles ferromagnetic behavior Fig. 5The Curie temperature $\mathrm{Tc}$ is in the range of 475 to $590 \mathrm{~K}$, which is lower in comparison to Tc $(718 \mathrm{~K})$ of $\mathrm{CaFe}_{12} \mathrm{O}_{19}$ due to substitution of $\mathrm{Al}^{+3}$ ions for magnetic $\mathrm{Fe}+3$ ions, which occupy the fivefold site [14]. The low value of Tc demonstrates that some intersublattice exchange interactions are strongly diminished. Moreover in hexaferrites the interaction between two close sites, such as $2 \mathrm{a}-12 \mathrm{~K}, 2 \mathrm{a}-4 \mathrm{f} 1$ and $2 \mathrm{~b}-12 \mathrm{~K}$, is decisive for strong magnetic character $[15,16]$.

Curie temperature, magnetization etc. increases due to the increase of strengthening of super exchange interaction. This increases due to magnetic ions i.e. $\mathrm{Fe}{ }^{+3}$, are present in these sites. The saturation magnetization $M_{s}$ and remanence $\mathrm{M}_{\mathrm{r}}$ of $\mathrm{M}$-type $\mathrm{Sr} \mathrm{La}_{\mathrm{y}} \mathrm{Fe}_{12-\mathrm{x}-\mathrm{y}} \mathrm{Al}_{\mathrm{x}} \mathrm{O}_{19}(0$ $\leq \mathrm{x} \leq 8)$ nanoparticles linearly decrease when $\mathrm{x}$ increases.as shown in fig. 5

Retentivity, (c) Coercivity, (d) Bohr Magneton, (e) Anisotropy Constant, (f) Mr/Ms

A mean field analysis of exchange interactions in M-type hexaferrite shows that $\mathrm{Fe}$ $(12 \mathrm{~K})$ sublattice making the link among octahedral R-S structural block, is subjected to very strong competitive exchange interactions. [17]Therefore, when the $\mathrm{Fe}^{+3}$ ions in the $12 \mathrm{~K}$ sublattice are subjected to ferromagnetic and non-magnetic ions viz. $\mathrm{Al}^{+3}$, the weakening of super exchange interaction between magnetic ions results

in lowering the magnetic intensity.

Table. 1- x-ray, density(dx), Mass density (d), Average grain size for the

compounds $\mathrm{SrLa}_{y} \mathrm{Al}_{\mathrm{x}} \mathrm{Fe}_{11-\mathrm{x}-\mathrm{y}} \mathrm{O}_{19}(0 \leq \mathrm{x} \leq 8)$

\begin{tabular}{|l|l|l|l|l|}
\hline Compounds & $\begin{array}{l}\text { x-ray } \\
\text { density } \\
(\mathrm{dx}),\end{array}$ & $\begin{array}{l}\text { Mass } \\
\text { density } \\
(\mathrm{d}),\end{array}$ & $\begin{array}{l}\text { Average } \\
\text { grain } \\
\text { size }\end{array}$ & $\begin{array}{l}\text { Porosity } \\
(\%)\end{array}$ \\
\hline $\mathrm{SrLaAlOFe}_{11} \mathrm{O}_{19}$ & 5.7105 & 2.6367 & 8.0362 & 53.82 \\
\hline $\mathrm{SrLaAl}_{2} \mathrm{Fe}_{9} \mathrm{O}_{19}$ & 5.4235 & 2.5427 & 49.2190 & 53.12 \\
\hline $\mathrm{SrLaAA}_{4} \mathrm{Fe}_{7} \mathrm{O}_{19}$ & 5.3819 & 2.2144 & 18.0139 & 49.87 \\
\hline $\mathrm{SrLaAL}_{6} \mathrm{Fe}_{5} \mathrm{O}_{19}$ & 4.63471 & 2.1078 & 7.2398 & 48.21 \\
\hline $\mathrm{SrLaAl}_{8} \mathrm{Fe}_{3} \mathrm{O}_{19}$ & 4.29422 & 2.0634 & 10.3546 & 46.12 \\
\hline
\end{tabular}

Table. 2- Lattice parameters 'a',c', Curie temperature (Tc)and Activation energy for the compounds

$\mathrm{SrLa}_{y} \mathrm{Al}_{\mathrm{x}} \mathrm{Fe}_{12-\mathrm{x}-\mathrm{y}} \mathrm{O}_{19}(0 \leq \mathrm{x} \leq 8)$

\begin{tabular}{|c|c|c|c|c|c|}
\hline \multirow[t]{2}{*}{ Compounds } & \multirow[t]{2}{*}{ a $(\AA \AA)$} & \multirow[t]{2}{*}{ c $(\AA)$} & \multirow{2}{*}{$\begin{array}{l}\text { Tc } \\
(\mathrm{K})\end{array}$} & \multicolumn{2}{|c|}{$\begin{array}{l}\text { Activation } \\
\text { Energy }\end{array}$} \\
\hline & & & & $\begin{array}{l}\text { Ferri } \\
(\mathrm{eV})\end{array}$ & $\begin{array}{l}\text { Para } \\
(\mathrm{eV})\end{array}$ \\
\hline $\mathrm{SrLaAl}_{0} \mathrm{Fe}_{11} \mathrm{O}_{19}$ & 5.86 & 22.36 & 475 & 0.3952 & 1.1106 \\
\hline $\mathrm{SrLaAl}_{2} \mathrm{Fe} \mathrm{O}_{19}$ & 5.98 & 22.08 & 518 & 0.4928 & 0.5473 \\
\hline $\mathrm{SrLaAl}_{4} \mathrm{Fe}_{7} \mathrm{O}_{19}$ & 5.89 & 21.51 & 528 & 0.5040 & 0.3860 \\
\hline $\mathrm{SrLaAL}_{6} \mathrm{Fe}_{5} \mathrm{O}_{19}$ & 5.86 & 21.16 & 590 & 0.5251 & 0.2420 \\
\hline $\mathrm{SrLaAl}_{8} \mathrm{Fe}_{3} \mathrm{O}_{19}$ & 5.95 & 21.08 & 604 & 0.5452 & 0.1671 \\
\hline
\end{tabular}

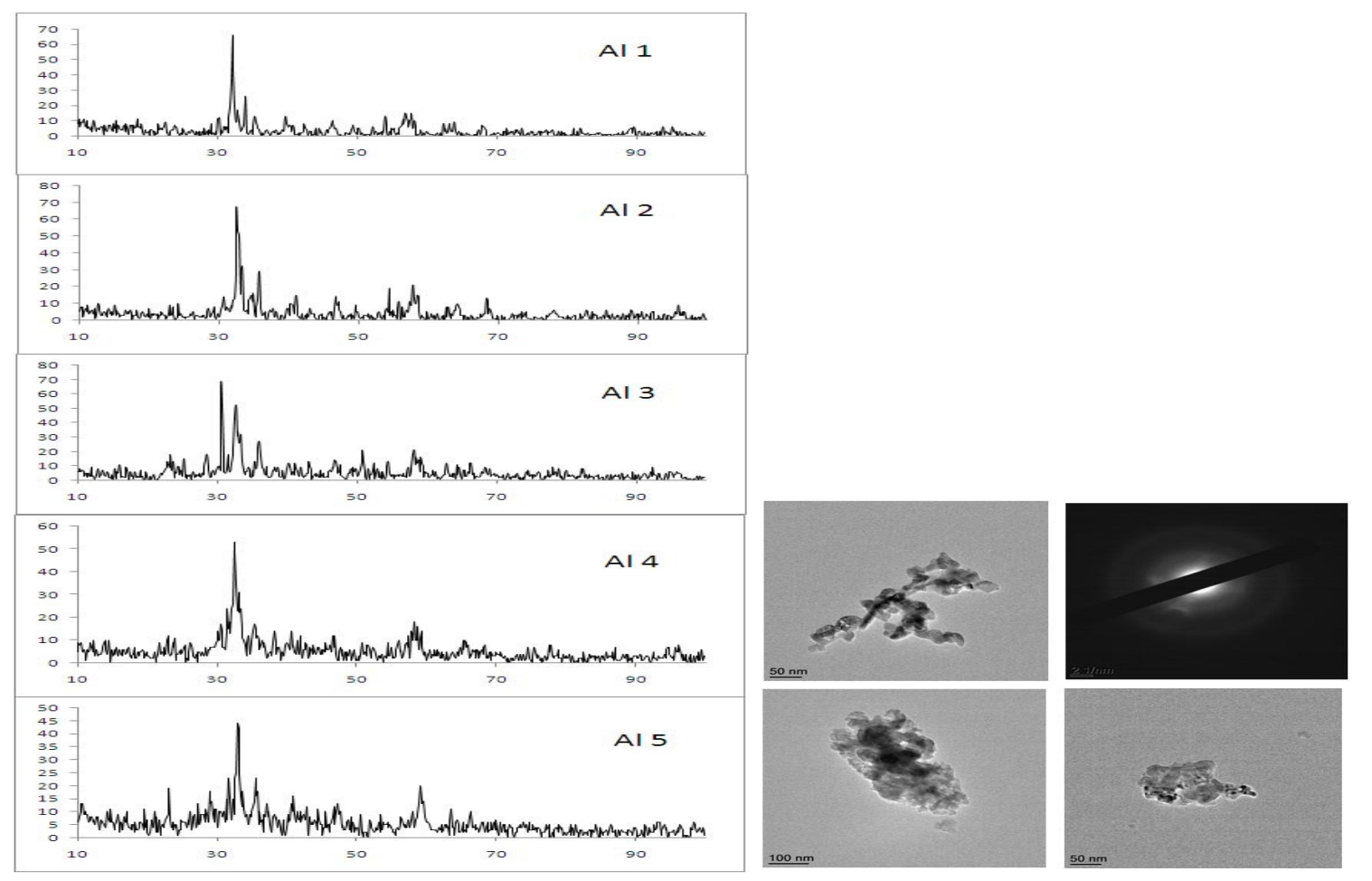

Figure. 1- XRD pattern of $\mathrm{Sr} L a_{y} A l_{x}$ $\mathrm{Fe}_{12-\mathrm{x}-\mathrm{y}} \mathrm{O}_{19}(\mathrm{x}=0-8)$ compound

Figure. 3-TEM results for sample $\mathrm{SrLa}_{y} \mathrm{Al}_{\mathrm{x}} \mathrm{Fe}_{11-\mathrm{x}-\mathrm{y}} \mathrm{O}_{19}$ 

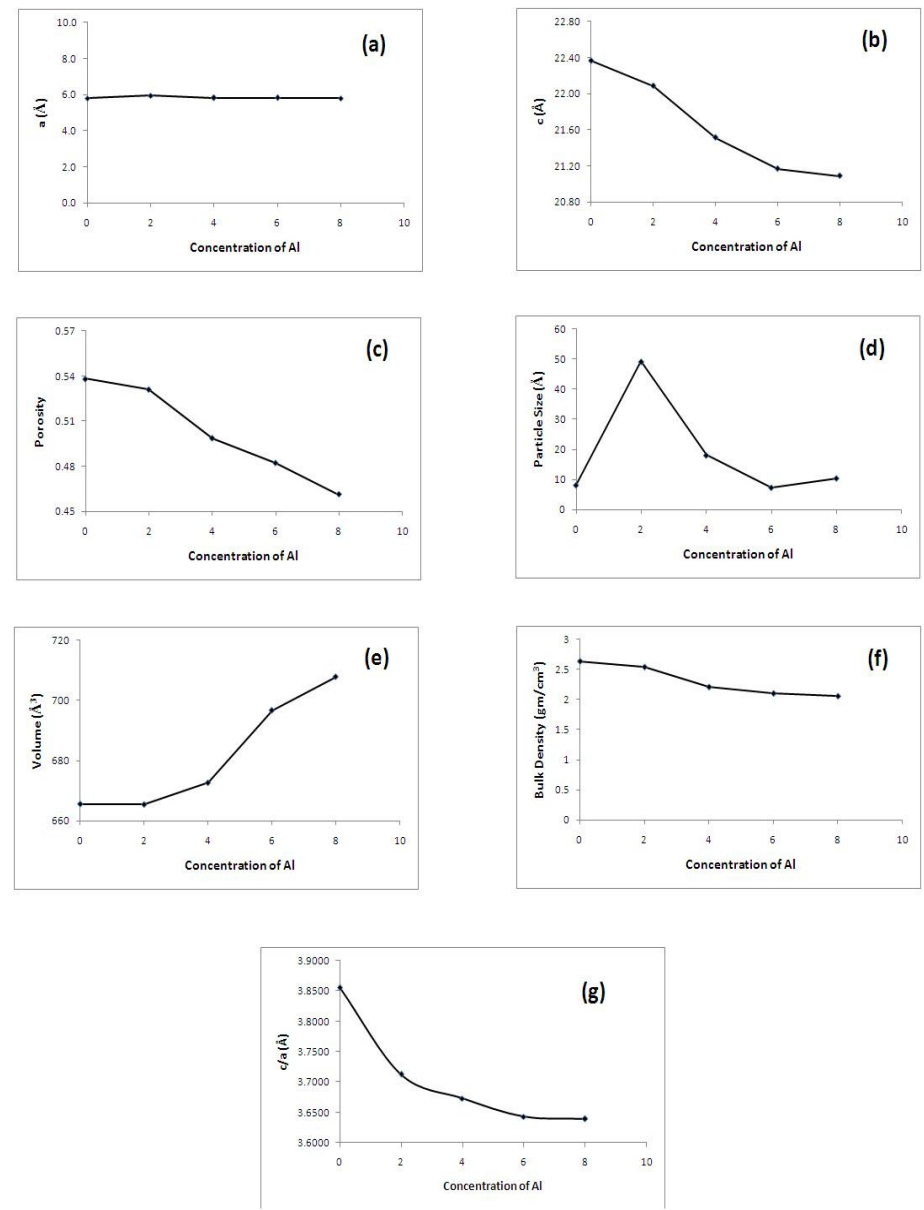

Figure. 3 (a) and (b) Lattice Parameters, (c) Porosity, (d) Particle Size, (e) Volume, (f) Bulk Density, (g) $\mathrm{c} / \mathrm{a}$

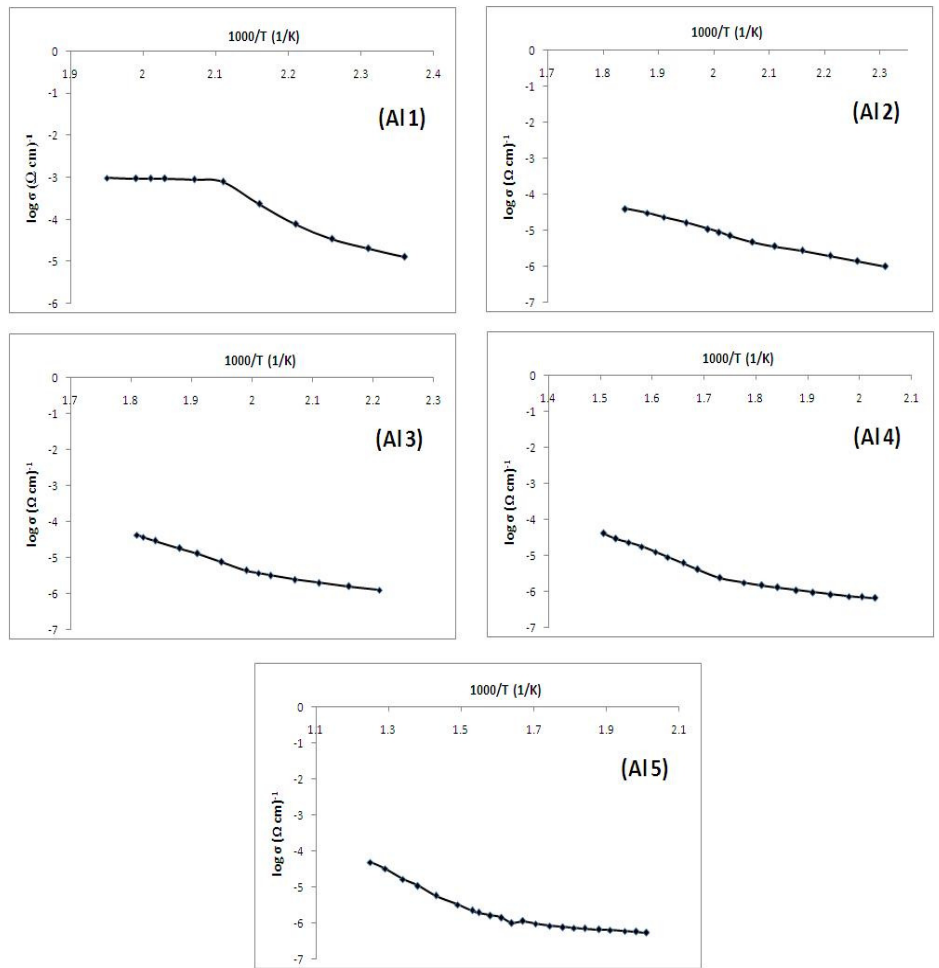

Figure. 4- Plots of Inverse of Temperature vs logarithmic conductivity of $\mathrm{Sr}_{\mathrm{Lay}} \mathrm{Al}_{\mathrm{x}} \mathrm{Fe}_{12-\mathrm{x}-\mathrm{y}} \mathrm{O}_{19} \mathrm{x}=0-8$ ) compounds 

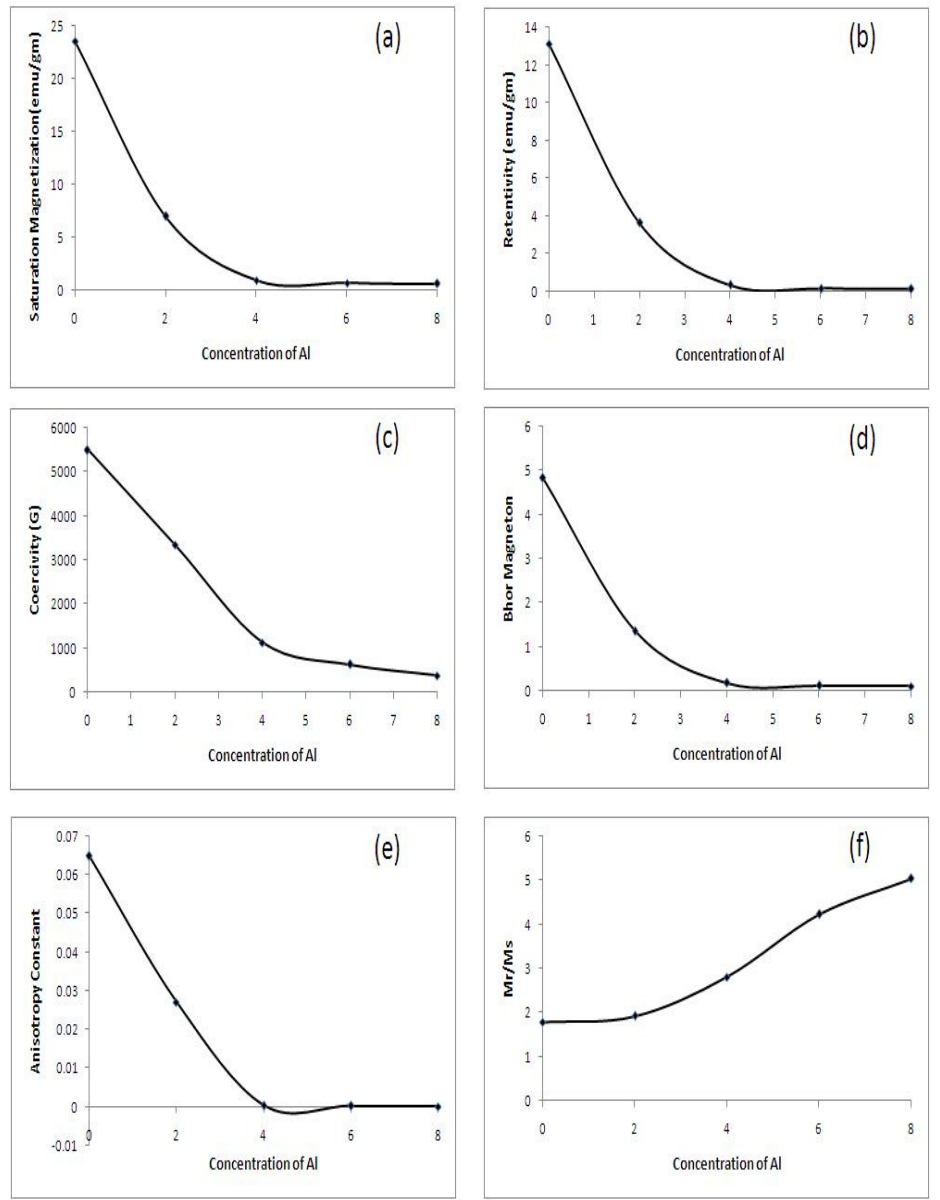

Figure. 5. Magnetic Parameters for $\mathrm{SrLaAl}_{\mathrm{x}} \mathrm{Fe}_{11-\mathrm{x}} \mathrm{O}_{19}(\mathrm{x}=0-8)$ (a) Saturation Magnetization, (b)

\section{Conclusions :}

TEM study reveals the hexagonal crystal structure of the ferrites. The average grain size of SrM-ferrites estimated from TEM studies, which in the range of $43.78 \mathrm{~nm}$ All the compounds have magnetoplumbite (Mstructure). The lattice parametersviz. 'a', 'c' and cell volume are found to decrease with increasing concentration of substituents $\mathrm{Al}^{+3}$. The activation energy in ferromagnetic region is observed to be less than that in paramagnetic region. X-ray density and bulk density of all the compounds decreases and porosity decreases with increasing $\mathrm{Mn}-\mathrm{Zn}$ concentration. The saturation magnetization $\mathrm{M}_{\mathrm{s}}$ and remanence $\mathrm{M}_{\mathrm{r}}$ of M-type nano particles linearly decrease when $\mathrm{x}$ increases.

\section{References :}

1. Heczko O, Gerber R and Šimša Z 2000 Thin Solid Films 358206

2. Choi D H, Lee S W, An S Y, Park S I, Shim I B and Kim C S 2003IEEE Trans. Magn. 39 2884
3. Wang X, Li D, Lu L and Wang X 1996 J. Alloys Compd. 23745

4. Sablea S N, Rewatkarb K G and Nanoti V M 2009 Mater. Sci. Eng.B168 156

5 Han M, Ou Y, Chen W and Deng L 2009 J. Alloys Compd. 474185

6. Chen N, Yang $\mathbf{K}$ and Gu M 2010 J. Alloys Compd. 490609

7. D.B. Ghare and A. P. B Sinha, Electrical investigations of $\mathrm{Ca} 2 \mathrm{Co} 2 \mathrm{Fe} 12 \mathrm{O} 22 . \mathrm{J}$. Phys. Chem. Solids 29, 885-888 (1968).

8. S. Suseela and A. P. B. Sinha, Crystallographic and electrical study of chromium substituted zinc copper ferrites. Indian J. Pure \& Appl. Phys. 11, 112-116 (1973).

9. M. K. Moinuddin and S. R. Murthy, Thermal expansion of $\mathrm{Mn}-\mathrm{Zn}$ ferrites in the manganese rich region.J. Alloys. Comp. 19(4), 105-109 
(1993).

10.Q Jianxun, G Mingyuan, S Haigen, J. of Magn. and Mag. Materials, 295, 263-268, (2005)

11.S. S. Darokar, K. G. Rewatkar, and D. K. Kulkarni, Synthesis and characterization of substituted $\mathrm{Ca}-$ hexaferritesMater. Chem. Phy. 56, 84-86 (1998)

12.Xi. Guoxi, Li Yunging, and Liu YuMin, Study of the magnetic properties of hydrothermally synthesized Srhexaferrites.Mater.Lett.58(7), 1664-1669 (2004).

13. N. Miyata, Phenomenology of the acoustic emission along hysteresis loop of polycrystalline ferrimagnets. J. Phys. Soc. Japan 16, 206-211 (1961).

14.X. Obradors, A. Islague, A. Collomb, M.
Pernet, J. Pannetier, J. Rpdriguez, J. Tejeda, and J. C.Joubert, Structural and magnetic properties of BaFe12-xMnxO19 hexagonal ferrites. IEEE Trans,

Magn.20, 1636-1644 (1984).

15. L. G. Van Uitert, Magnetic and structural

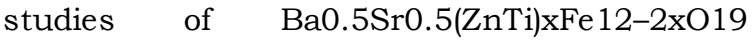
prepared byballing milling.J. Appl. Phys, 28, 317-319 (1957).

16. G. Turilli, F. Liai, S. Rinaldi, and $\mathbf{P}$. Denill, Preparation of substituted barium ferriteBaFe 12-x(Ti0.5Co0.5)xO19. J. Magn. Magn.Mater 59, 127-132 (1986).

17. A. Isalgue, A. Laberta, J. Tejada, and $\mathbf{X}$. Obradors, Study of some structural and magneticpeoperties of Mn-substituted $\mathrm{SrCu}$ hexagonal ferites. J. Appl. Phy. A-39, 221-226 (1986). 